\title{
Desafios da Ferrovia de Integração do Centro-Oeste no Cerrado
}

\author{
Jeferson de Castro Vieira \\ Programa de Pós-Graduação em Desenvolvimento e Planejamento Territorial da Pontifícia Universidade Católica \\ de Goiás (Puc/Goiás)
}

Recebido: 23/11/2015 Versão revisada (entregue): 27/02/2016 Aprovado: 04/03/2016

\begin{abstract}
Resumo
Este artigo analisa a importância da construção da Ferrovia de Integração do Centro-Oeste (FICO) para a economia do Cerrado. Destaca a evolução do transporte ferroviário brasileiro e sua retomada no contexto atual do desenvolvimento econômico do país. Enfatiza a programação de investimentos em infraestrutura no Brasil, que precisa ser muito bem definida do ponto de vista econômico e social para minorar numerosos pontos de estrangulamento do desenvolvimento nacional. Apresenta a construção da FICO e de sua integração com as malhas ferroviárias brasileiras como contribuição para o aumento e o escoamento da produção agropecuária desta parte da região do Centro-Oeste. Por fim, recomenda uma agenda de desenvolvimento regional que possa integrar, de forma eficiente, a ferrovia com as forças produtivas e sociais da região em questão.
\end{abstract}

Palavras-chave | Centro-Oeste; cerrado; desenvolvimento regional; Ferrovia de Integração do Centro-Oeste.

Código JEL | L92; O18; R58.

\section{CHALLENGES OF THE BRAZILIAN MIDWEST INTEGRATION RAILROAD IN CERRADO}

\begin{abstract}
This paper analyzes the importance of the Midwest Railroad Integration (FICO) construction for the economy in the Brazilian biome Cerrado. It highlights the evolution of Brazilian railroad transport and its recovery in the current economic development context. It emphasizes the infrastructure investments programming in Brazil that needs to be well defined, regarding economic and social matters to mitigate the bottlenecks of national development. It shows FICO construction and its integration with Brazilian railroad network to contribute to increase and distribution of agricultural production in the Midwest region. In conclusion, it recommends a regional development agenda that can integrate efficiently the railroad with the productive and social forces in the mentioned region.
\end{abstract}

Keywords | Brazilian Midwest Integration Railroad; Cerrado; Midwest; regional development.

JEL-Code | L92; O18; R58. 


\section{RETOS DEL FERROCARRIL DE LA INTEGRACIÓN DEL CENTRO-OESTE BRASILEÑO EN EL CERRADO}

\section{Resumen}

Este artículo analiza la importancia de la construcción del Ferrocarril de la Integración CentroOeste (FICO) para la economía del Cerrado. Destaca la evolución del transporte brasileño en ferrocarriles y su retomada en el actual contexto del desarrollo económico. Enfatiza la programación de inversiones en infraestructuras en el Brasil, que necesita estar muy bien definida del punto de vista económico y social para reducir los puntos de estrangulamiento del desarrollo nacional. La construcción del FICO y su integración con la red brasileña de ferrocarriles contribuye al incremento y la salida de la producción agropecuaria de la región Centro-Oeste. Por último, se recomienda una agenda para el desarrollo regional que pueda integrar de modo eficiente el FICO con las fuerzas productivas y sociales de esa región en cuestión.

Palabras-clave | Centro-Oeste; Cerrado; desarrollo regional; Ferrocarril de la Integración del Centro-Oeste.

Código JEL | L92; O18; R58.

\section{Introdução}

O presente artigo tem como finalidade analisar e compreender a importância da construção da Ferrovia de Integração do Centro-Oeste (FICO) para a economia do Cerrado. Como recorte territorial de uma ferrovia ainda em projeto de construção, a delimitação do objeto em estudo se limitará aos estados de Goiás e Mato Grosso, entre as cidades de Campinorte e Lucas do Rio Verde.

A escolha deste tema é decorrente do Projeto de Integração do Cerrado (PróIntegração - UFG, Unicamp e PUC Goiás), que analisa a integração das malhas ferroviárias e rodoviárias na região de expansão do Cerrado. Tendo em vista a retomada do desenvolvimento econômico brasileiro por uma ótica do setor de infraestrutura, com destaque especial para as ferrovias, percebe-se que há uma lacuna de estudos sobre a economia da região Centro-Oeste no que se refere ao modal de transporte ferroviário.

Percebe-se que nessas últimas décadas houve um esforço enorme de desenvolvimento regional brasileiro com políticas de inclusão social, que minoraram os enormes desequilíbrios regionais, mas ainda persistem imensos desafios de integração de suas regiões. Sendo assim, há uma agenda aberta de investimentos infraestruturais no Brasil que precisa ser muito bem definida do ponto de vista econômico e social, de forma que possa minorar os pontos de estrangulamento do desenvolvimento econômico.

Neste contexto, o setor ferroviário, com seu efeito multiplicador de oportunidades de negócios, geração de empregos e renda, deve ser visto como um dos 
instrumentos importantes para reduzir e integrar as regiões brasileiras. Portanto, a hipótese deste artigo é a de que a construção da FICO e sua integração com as malhas ferroviárias brasileiras deve contribuir para o aumento da produção e escoamento da produção agropecuária desta parte da região do Centro-Oeste.

Para sustentar esta hipótese, pressupõe-se que a agropecuária forma a base para o desenvolvimento da economia regional. Desta maneira, investimentos neste segmento têm um efeito de encadeamento produtivo para frente e para trás muito forte, com formação de conglomerados em torno da agricultura, pecuária, segmentos industriais e de prestação de serviços que posteriormente se diversificam, à medida que novos mercados locais e regionais consolidam-se.

Neste sentido, este artigo é dividido em quatro partes. Na primeira, contextualizase o processo de planejamento e desenvolvimento do transporte ferroviário brasileiro desde as primeiras malhas ferroviárias até os dias atuais. Em seguida, é demonstrada a relação entre desenvolvimento regional e sua articulação com os modais de transporte de carga, dando destaque para o ferroviário. Na terceira, são apresentadas as perspectivas e importância da FICO para o desenvolvimento dessa área de expansão agropecuária do Centro-Oeste. Nas conclusões, recomenda-se uma agenda de desenvolvimento regional que possa integrar de forma producente a ferrovia com as forças produtivas e sociais da região em tela.

\section{Processo de planejamento e desenvolvimento do transporte ferroviário brasileiro}

Do ponto de vista do desenvolvimento regional, conforme Lanna (2012) e De Paula (2000), as ferrovias têm papel importante na formação e no crescimento de cidades brasileiras. Os autores reportam que em torno das cidades são constituídos espaços econômicos e sociais com ampliação da população e novas demandas por serviços e comércio, o que encurta distâncias e altera completamente a noção de territorialidade. Assim, a ferrovia, como parte constituinte de novas territorialidades econômicas, ao incorporar em seu tecido urbano atores econômicos e sociais, simboliza um canal de integração local e regional ao aglutinar e estimular o desenvolvimento de atividades produtivas voltadas tanto para o mercado interno quanto externo.

Do ponto de vista histórico, segundo Barat (1991) e Galvão (2009), as ferrovias tiveram papel primordial no ciclo de exportação de produtos primários (entre 1880 e 1930), entrando em decadência em meados do século XX. Nesse sentido, a rápida industrialização do País e a necessidade de consolidação do mercado interno induziram à opção pelo transporte das cargas industriais por caminhões, dada a incompatibilidade das malhas ferroviárias com essa nova função. Assim, o rápido deslocamento das fronteiras agrícolas, a maior diversidade de pontos de 
origem e destino, o maior fracionamento das cargas devido à industrialização, fizeram com que as rodovias fossem mais aptas a responder rapidamente aos desafios da nova configuração econômica do País.

Barat (1991) ainda afirma que, apesar do grande volume de recursos destinados às ferrovias a partir dos anos 1950, a redução dos investimentos na malha ferroviária foi drástica devido à crise fiscal dos anos 1980. Segundo Silveira (2003), a fase de decadência inicia-se a partir da década de 1970, quando todo o sistema ferroviário no Brasil é desestruturado, em razão da maturação e da concorrência com o modal rodoviário (rodovias federais, estaduais e municipais) e também devido à falta de investimentos no setor ferroviário pelo Estado e pela iniciativa privada. Silveira (2003) retrata que esse período durou até a metade da década de 1990, quando foram desativados no Brasil cerca de 8.000 quilômetros de extensão ferroviária devido a uma drástica redução da poupança pública, inibindo investimentos estatais em setores fundamentais da sociedade. Tal incapacidade do Estado brasileiro trouxe a deficiência para muitos setores de infraestrutura, como o ferroviário.

Nota-se que desde 1996 o sistema ferroviário brasileiro foi objeto de concessões, por meio do arrendamento dos ativos operacionais. Em um relatório do BNDES (2000) são listados os principais motivos e expectativas que levaram à concessão das malhas ferroviárias do País. São eles: (a) a geração de investimentos na recuperação, modernização e ampliação da infraestrutura existente; (b) captação de recursos privados a fim de alavancar recursos adicionais ao setor; (c) redução do número de acidentes e aumento da produção; (d) retomada de encomendas de equipamentos e novos sistemas, bem como recuperação do material rodante degradado, à indústria ferroviária nacional, que se encontrava ociosa; e (e) capacitação da ferrovia para assumir um novo papel na matriz modal brasileira.

Segundo estudos do GEIPOT (2001), na década de 1990, as políticas econômicas trouxeram novos desafios para os setores econômico, logístico e de transportes, retomando o discurso sobre a necessidade de melhorar a eficiência do sistema logístico brasileiro para integrá-lo à economia internacional. Dessa feita, identificou-se a necessidade de investir nos eixos viários para atender à demanda do sistema produtivo, na medida em que o transporte tornou-se um instrumento importante na expansão dos eixos de desenvolvimento nacional e/ou regional

Ainda segundo o GEIPOT (2001), na questão da política de transportes, o Estado Brasileiro buscou estratégias de desenvolvimento pautado nos planos de governo, o "Brasil em Ação" e "Avança Brasil", com a ideia de transformar o Estado Brasileiro de provedor em poder concedente e regulador, aprimorando, em contrapartida, sua capacidade de coordenação, normatização e supervisão. Assim, como diretriz básica visava garantir eficiência à matriz de transportes e a redução dos custos sistêmicos (Custo Brasil) da economia brasileira. 
Assim, o processo de privatização das ferrovias teve como objetivo atrair investimentos para sua recuperação e capacitar o sistema para assumir um novo papel na matriz modal brasileira. As metas do Governo Federal foram traçadas com objetivo de aumentar a participação e melhorar a qualidade do modal para o transporte de cargas agrícolas e minérios, visando impactos positivos no custo das mercadorias consumidas no mercado interno e na competitividade dos produtos brasileiros no mercado internacional.

Dessa forma, o Governo Federal, por meio do Ministério dos Transportes e do Ministério da Defesa, elaborou o Plano Nacional de Logística e Transportes (PNLT) (2007). Assim, o PNLT marca a retomada do processo de planejamento estatal no setor de transportes, superando um gargalo de mais de 20 anos de falta de estudos para o setor logístico nacional. Portanto, o PNLT é um plano indicativo de investimentos para o período 2007-2022, baseado em projeções da evolução econômica nas diferentes regiões do País e na respectiva geração de demanda por transporte de carga sobre a malha viária brasileira em seus diversos modais.

Assim, o PNLT é guiado por cinco objetivos:

i) Retomada do processo de planejamento no setor dos transportes;

ii) Melhoria da eficiência e competitividade da economia nacional frente à realidade do mercado doméstico e internacional, por meio de uma consideração dos custos de toda a cadeia logística que permeia o processo que se estabelece entre as origens e destinos dos fluxos de transporte;

iii) Melhor equilíbrio da matriz de transporte de carga no País;

iv) Preservação ambiental, buscando-se respeitar as áreas de restrição e controle de uso do solo, seja na questão de produção de bens, seja na implantação da infraestrutura;

v) Enquadramento dos projetos estruturantes do desenvolvimento socioeconômico do País por categorias (aumento da eficiência produtiva em áreas consolidadas, redução de desigualdades regionais em áreas deprimidas, integração regional sul-americana e indução ao desenvolvimento de áreas de expansão de fronteira agrícola e mineral).

Nesse processo de retomada do planejamento no setor logístico, o Governo Federal reestruturou a empresa estatal VALEC (Engenharia, Construções e Ferrovias S.A.) em 2008. Foi atribuída à VALEC a função de construir e explorar a infraestrutura ferroviária, assim como coordenar, executar, controlar, revisar, fiscalizar e administrar obras de infraestrutura ferroviária que lhe forem outorgadas.

Nessa mesma direção, o Governo Federal brasileiro lançou em 2012 o Programa de Investimentos em Logística (PIL). O programa inclui um conjunto de projetos 
com propósito de contribuir para o desenvolvimento de um sistema de transportes moderno e eficiente, a ser conduzido por meio de parcerias estratégicas com o setor privado, promovendo-se sinergias entre as redes rodoviária e ferroviária, hidroviária, portuária e aeroportuária. Segundo a ANTT (2014), a extensão da malha ferroviária em 2014 era de 29,1 mil quilômetros, operada por 11 concessionárias. Trata-se da $10^{\mathrm{a}}$ maior malha ferroviária do mundo, com predominância do transporte de minério de ferro $(66 \%)$, complexo de soja e farelo (10\%), além de cimento, produtos siderúrgicos e carvão.

Para se ter uma dimensão de valores, conforme dados da ANT'T (2014), estão previstos R \$ 91 bilhões de investimentos em construção e/ou melhoramentos de 11 mil quilômetros de linhas férreas relacionados ao PIL nas ferrovias brasileiras no período de 2014-2038. Isso implica que o PIL tem como diretrizes principais a provisão de uma rede ferroviária ampla, moderna e integrada; cadeias de suprimentos eficientes e competitivas; e modicidade tarifária.

Logo, o Programa contempla um novo modelo de concessão, em que os concessionários são gestores da infraestrutura ferroviária, responsáveis pela infraestrutura, sinalização e controle da circulação de trens. A concessão, pelo prazo de 35 anos, propõe contemplar ferrovias de bitola larga $(1.600 \mathrm{~mm})$ com alta capacidade de carga e traçado geométrico otimizado que permita maiores velocidades $(80 \mathrm{~km} / \mathrm{h})$.

Nessa trajetória, o projeto da FICO, no trecho entre Lucas do Rio Verde (Mato Grosso) e Campinorte (Goiás), com uma extensão aproximada de 883 quilômetros, deve ser visto como um instrumento que pode produzir resultados relevantes para o desenvolvimento regional. Dessa forma, espera-se que a implementação deste novo trecho possa ser uma alternativa logística para o transporte e escoamento de grãos (soja, milho), além de outros produtos agrícolas com integração com a Ferrovia Norte-Sul.

\section{Desenvolvimento regional e necessidade de ferrovias}

A ferrovia é considerada como elemento integrador que estabelece relações econômicas, sociais e urbanas de sociedades, engrenando o desenvolvimento de cidades que estão às suas margens. Como trajetória, a ferrovia dinamiza o comércio e a produção local, formando, em um primeiro momento, um entreposto comercial. Já em um segundo movimento, as transformações ocorridas em uma determinada localidade podem consolidar uma dada região ou mesmo constituir cidades-polo. Nesse sentido, a área de influência de uma ferrovia deve ser vista com efeito dinamizador da economia e de inserção da economia local/regional na nacional ou mesmo internacional. 
Nesse aspecto, um debate interessante sobre acessibilidade em um contexto de desenvolvimento regional é retratado por Castro (2001), que elaborou parâmetros de acessibilidade, encontrando diferenciais significativos entre as regiões. Nesse quesito da realidade brasileira, observa-se a coexistência da concentração espacial da renda conjugada com provisão da infraestrutura desbalanceada entre as regiões (BARROS; RAPOSO, 2002). Os mercados mais sólidos concentram-se nas regiões Sul e Sudeste, que também têm melhor dotação de provisão na infraestrutura ferroviária.

Nesse sentido, há uma discussão no Brasil sobre o melhor sistema de transporte. Em boa parte da União Europeia o sistema de transporte ferroviário é largamente utilizado para transportar cargas e passageiros e, na maioria das vezes, de forma mais eficiente que as rodovias. O mesmo acontece na maior parte dos Estados Unidos da América. Esse debate precisa de uma adequação para o sistema de transporte brasileiro a fim de verificar qual sistema tem se mostrado mais eficiente. A alternativa crível tem sido uma mescla dos modais rodoviário e ferroviário, conforme demonstrado na Tabela 1.

Observando a Tabela 1, verifica-se que a ferrovia é rígida em sua topologia de transporte, não possuindo a flexibilidade ponto a ponto do transporte rodoviário. A capacidade de carga da ferrovia, porém é alta; já a do transporte rodoviário média-baixa. Em compensação, os custos fixos ferroviários são altos, enquanto os rodoviários médios. Os custos variáveis são médios para ferrovia e rodovia.

Tabela 1 Aspectos característicos de cada modalidade de transporte

\begin{tabular}{ccccc}
\hline Modais & Topológico & $\begin{array}{c}\text { Capacidade de } \\
\text { carga }\end{array}$ & Custos fixos & $\begin{array}{c}\text { Custos } \\
\text { variáveis }\end{array}$ \\
\hline Ferrovia & $\begin{array}{c}\text { Rígido Terminal a } \\
\text { Terminal }\end{array}$ & Alta & Altos & Médios \\
Rodovia & $\begin{array}{c}\text { Grande Flexibilidade } \\
\text { Ponto a Ponto } \\
\text { Régido Terminal a } \\
\text { Terovia }\end{array}$ & Média-baixa & Médios & Médios \\
\hline
\end{tabular}

Fonte: Nazário et al., 2000.

Conforme Campos Neto et al.(2010), no Brasil o modal ferroviário cumpre um importante papel no mercado exportador de grãos e minérios, uma vez que se mostra mais adequado ao transporte de produtos não perecíveis e de baixo valor agregado. Contudo, possui um alcance bastante limitado no transporte de cargas em geral. Do ponto de vista da competitividade, a ferrovia atende à demanda 
estadual de transporte de volumes de carga cada vez maior, de forma mais econômica e segura, para longas distâncias. A demanda por esse tipo de transporte pode ser atendida pelos modais ferroviários e rodoviários.

A ESALQ (Escola Superior de Agricultura Luiz de Queiroz) realizou em 2009 um estudo sobre o transporte multimodal de safras agrícolas pelo corredor CentroOeste, feito em parceria com UFMT (Universidade Federal do Mato Grosso), conhecida como ESALQ-LOG. Considera como corredor os estados de Mato Grosso, Mato Grosso do Sul, Goiás, Minas Gerais, São Paulo e Paraná.

\section{Tabela 2 Matriz de transporte estimada a partir das quantidades movimentadas declaradas pelos entrevistados}

\begin{tabular}{crrrr}
\hline \multirow{2}{*}{ Carga } & \multicolumn{2}{c}{ Matriz de Transporte } & \multirow{2}{*}{ Total } \\
\cline { 2 - 3 } & Rodoviário & Ferroviário & Hidroviário & \\
\hline Graneis agrícolas sólidos & $79 \%$ & $18 \%$ & $3 \%$ & $100 \%$ \\
Graneis agrícolas líquidos & $87 \%$ & $11 \%$ & $2 \%$ & $100 \%$ \\
\hline
\end{tabular}

Fonte: ESALQ-LOG (2009).

Nota-se na Tabela 2 a forte predominância do transporte rodoviário na região, demonstrando também grande espaço para o desenvolvimento do transporte ferroviário. Dessa forma, foi elaborado o índice de disponibilidade declarada de modais de transporte para o corredor Centro-Oeste, conforme Tabela 3.

Extrai-se da Tabela 3 que a oferta de rodovias mostra-se bem superior aos de outras modalidades. Em seguida, as ferrovias têm participação muito baixa, quase nula. A oferta de transporte ferroviário, quando se junta à disponibilidade de rodovias em certos trajetos, é alta, principalmente em alguns tipos de carga como açúcar, óleo de soja, graneis líquidos e álcool. Nesse cenário, há maior oportunidade de aumentar a oferta de ferrovias.

A pesquisa da ESALQ-LOG (2009) também indica que no corredor Centro-Oeste os transportadores entrevistados declararam existir gargalos no sistema de transporte, sendo os principais: infraestrutura viária deficiente (81\%); oferta insuficiente de serviço de transporte (46\%); alto custo do frete (30\%); falta de modal alternativo $(18 \%)$. 
Tabela 3 Índice de disponibilidade de modais de transporte para o Corredor Centro-Oeste

\begin{tabular}{lcccc}
\hline \multirow{2}{*}{ Carga } & \multicolumn{4}{c}{ Modal disponível } \\
\cline { 2 - 5 } & Apenas R & Apenas F & R e F & Outros \\
\hline Açúcar & $48,5 \%$ & $0,0 \%$ & $49,0 \%$ & $2,5 \%$ \\
Farelo de soja & $45,1 \%$ & $6,5 \%$ & $31,5 \%$ & $16,9 \%$ \\
Fertilizantes & $63,4 \%$ & $0,8 \%$ & $35,8 \%$ & $0,0 \%$ \\
Milho & $61,6 \%$ & $0,1 \%$ & $27,1 \%$ & $11,2 \%$ \\
Soja & $70,2 \%$ & $0,7 \%$ & $20,7 \%$ & $8,4 \%$ \\
Trigo & $64,7 \%$ & $0,0 \%$ & $26,0 \%$ & $9,3 \%$ \\
Álcool & $52,2 \%$ & $0,0 \%$ & $41,9 \%$ & $5,9 \%$ \\
Óleo de soja & $42,8 \%$ & $0,0 \%$ & $48,3 \%$ & $8,9 \%$ \\
Graneis sólidos & $67,9 \%$ & $0,0 \%$ & $24,5 \%$ & $7,6 \%$ \\
Graneis líquidos & $49,9 \%$ & $0,0 \%$ & $43,5 \%$ & $6,6 \%$ \\
\hline
\end{tabular}

Fonte: Elaborada pelo autor com base em ESALQ-LOG (2009).

Nota: $\mathrm{R}=$ Rodoviário; $\mathrm{F}=$ Ferroviário.

Numa dimensão regional, uma hipótese que deve ser trabalhada é a de que altos custos logísticos do atendimento de mercados mais distantes ou de menor escala tendem a reforçar a concentração de renda. Neste aspecto, regiões menos favorecidas na dotação da infraestrutura, como a Centro-Oeste, ficam pouco competitivas para atrair negócios em razão dos elevados custos incorridos para o suprimento e para a distribuição dos produtos nos mercados, uma vez que os diferenciais de custos de produção eventualmente existentes perdem preponderância na análise dos custos totais.

Isso aponta para uma melhora na posição relativa do indicador de infraestrutura ferroviária que pode gerar uma elevação de produtividade na região. Dessa forma, na medida em que a produtividade se eleva, a área de fronteira agrícola que em muitas sub-regiões era economicamente inviável passa a ser viável, e a produção agregada se eleva. No caso da região da FICO, pressupõe que fluxos de cargas possam formar corredores de concentração de renda. Nesse aspecto, investimentos complementares são necessários para que externalidades negativas não possam sobrepor às externalidades positivas.

Logo, a consolidação do processo de desenvolvimento requer investimentos diversificados e coordenados entre os modais de transporte, para viabilizar a 
desejável expansão horizontal, vertical e espacial da economia regional. Neste aspecto, estudos e pesquisas de órgãos públicos brasileiros e universidades precisam viabilizar a maneira mais racional de ocupar o Cerrado brasileiro, com seus milhões de hectares aptos a serem explorados pela agricultura e pecuária.

Nesta estrutura de abordagem, os corredores de transporte se sobressaem e passam a concentrar a atenção dos planejadores. Segundo Barat (1972), corredores de transporte são caracterizados como segmentos dos sistemas de transporte, ligando áreas ou localidades, entre os quais ocorre demanda por transporte para viabilizar fluxo de mercadoria de densidade em termos nacionais.

Assim, o conceito de corredor é bastante relevante na análise regional. A visão moderna de corredor evoluiu de simples vias de transporte para uma abordagem holística que contempla as cadeias de suprimento que ocupam os espaços econômicos pré-definidos. Isso implica que os fluxos de comércio encontram sistemas de transporte aptos a suportar a movimentação de bens, serviços e pessoas. Entretanto, Barat (1972) chama a atenção para o fato de que estes sistemas precisam ser complementados com estruturas também complexas, tais como mercados de trabalho e de capital, infraestrutura comercial, compreendendo condições de armazenamento e distribuição, sistema regulatório, integração tecnológica, espaços de produção e disseminação de ciência e tecnologia, sistemas de transporte complementares e condições de acessibilidade aos mercados locais, regionais, nacionais e internacionais.

\section{Perspectivas de desenvolvimento para a região}

Conforme VALEC (2009), Goiás e Mato Grosso participam da expansão da fronteira agrícola brasileira com ganhos de escala de produção crescentes. A mais recente experiência de expansão da fronteira agrícola no Brasil ocorreu no norte do Tocantins e no sul do Maranhão, em virtude da entrada em operação do primeiro trecho da Ferrovia Norte-Sul. Há dificuldade de se ampliar a fronteira agrícola usando o modal rodoviário. É visível a contribuição potencial da Ferrovia de Integração Centro-Oeste, ao propiciar excelentes condições para a expansão das fronteiras agrícolas. No Gráfico 1 verifica-se que entre 2002 e 2015 (previsão da safra) a produção de grãos do Centro-Oeste cresceu $160 \%$ contra $102 \%$ no Brasil no mesmo período. 


\section{Gráfico 1 Produção de grãos, Brasil e Centro-Oeste, 2002-2015}

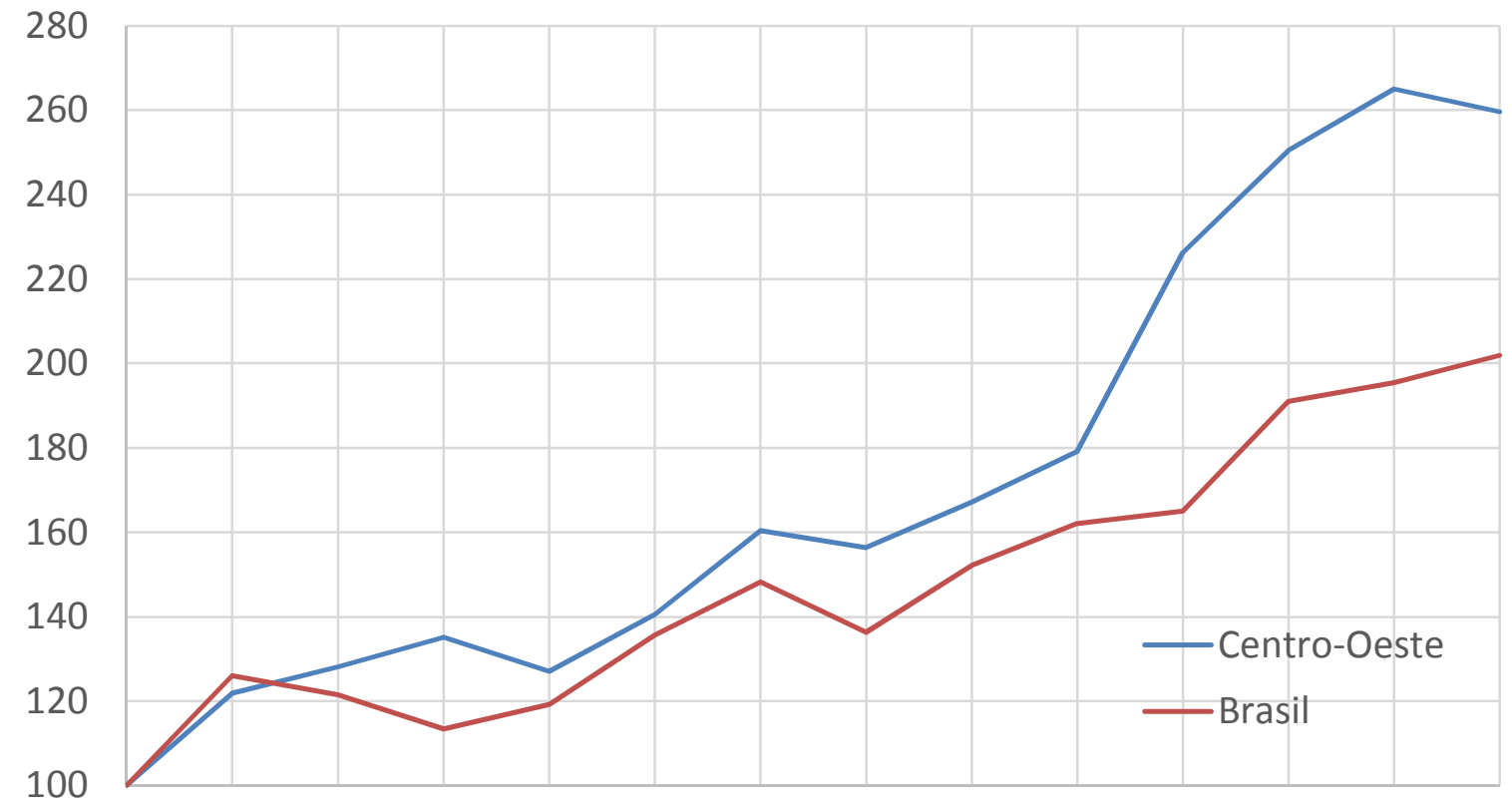

20022003200420052006200720082009201020112012201320142015

Fonte: IBGE, Produção Agrícola.

Diante dessa condição de reduzida participação do modal ferroviário de cargas, em especial para as cargas agrícolas, o cenário apresentado pela VALEC (2009), baseado em propostas do governo e do setor privado, tenta promover a participação da ferrovia no transporte de carga, tanto para atender à demanda reprimida atualmente para o transporte ferroviário, quanto para o aumento de demanda promovido pela maior produção agrícola e mineral prevista para os próximos 15 anos. Parte desse aumento de produção só é viável se existirem condições adequadas, em capacidade e custo, para escoar tal produção, o que o modal ferroviário é, em muitos casos, o mais adequado.

As dimensões continentais do Brasil há muito tempo redundam em impasses para sua integração econômica e territorial, principalmente em razão das enormes distâncias entre seus centros regionais. Logo, a incorporação do interior à economia nacional passa pelo fortalecimento e expansão do mercado interno, o que pressupõe um bom sistema de meios de transporte frente à integração nacional. Neste aspecto, a FICO pode contribuir para integrar nacionalmente, ou seja, representa uma oportunidade para ampliação dos mercados regionais ao mercado nacional. Significa também que a partir da construção da FICO, o País possa ampliar seu grau interno de complementaridade agropecuária com segmentos agroindustriais e participação na produção de riqueza nacional.

O Gráfico 2 apresenta um aumento nominal do PIB (Produto Interno Bruto), no período de 2002-2012, de 232\% na região Centro-Oeste contra 197\% no Brasil. 
Isso significa que a expansão agrícola tem sido acompanhada de uma expansão da riqueza bem acima da média nacional.

\section{Gráfico 2 Produto Interno Bruto, Brasil e Centro-Oeste, 2002-2012}

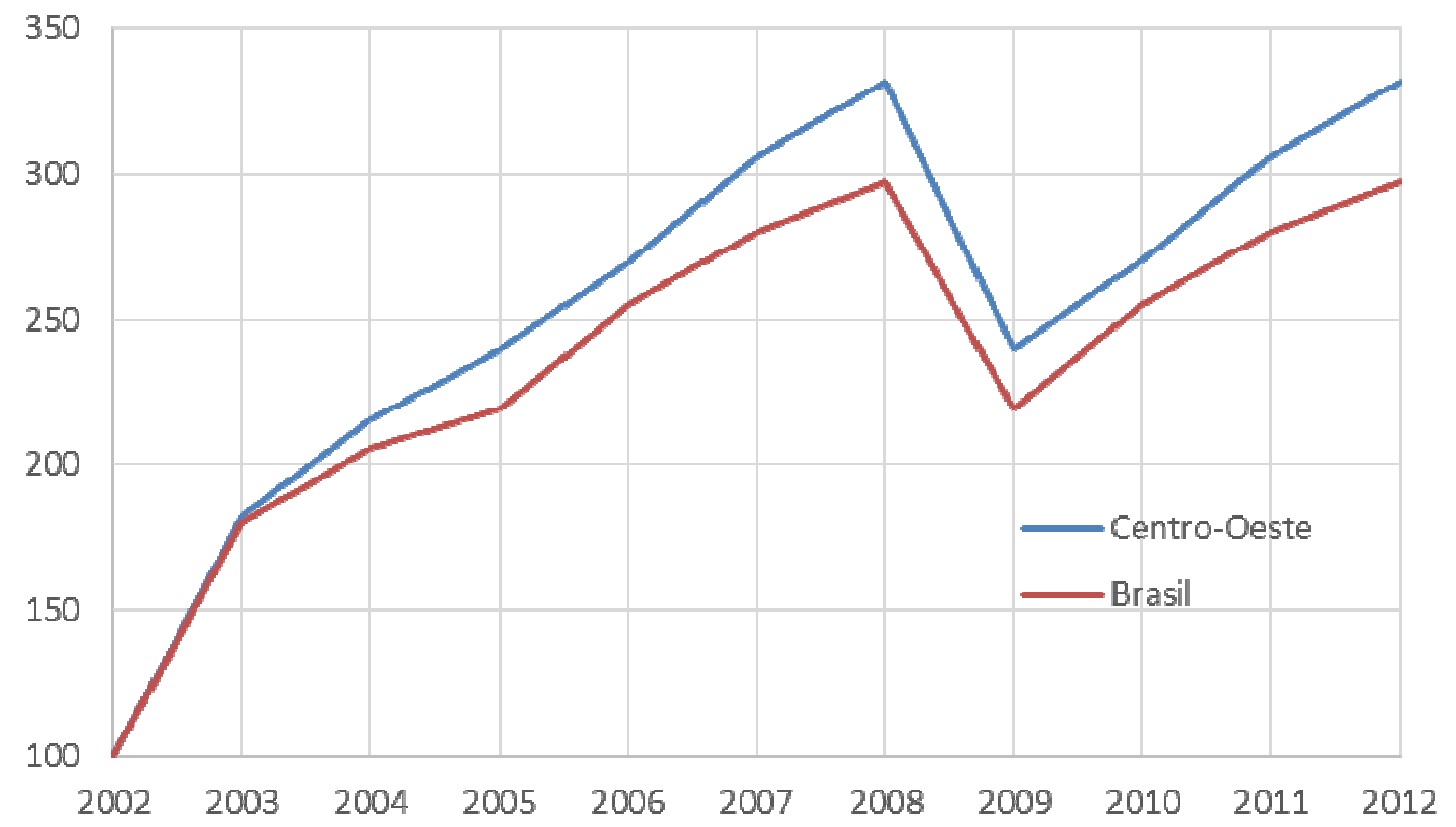

Fonte: IBGE, Contas Regionais.

A agricultura brasileira tem operado em níveis ascendentes de produtividade, entendida esta como o volume de produtos obtidos por unidade de área. Sob esta ótica, a elevação da produção por área tem sido, nas últimas décadas, na região do Cerrado, uma meta prioritária perseguida pela política econômica para o setor. $\mathrm{O}$ crescimento da produtividade agrícola acelerou devido ao ritmo de desenvolvimento que assumiu o progresso técnico. Assim, pode-se vislumbrar a importância que adquire, então, a elevação da produtividade da agricultura neste contexto, pois a agropecuária constitui um dos setores prioritários no fornecimento de insumos que participam diretamente da produção de riqueza.

Assim, no Cerrado brasileiro, a expansão de novos processos produtivos agropecuários tem se dado pela diversidade dos recursos naturais disponíveis, principalmente a qualidade das terras, o grau de tecnificação da agricultura e o tipo de atividade desenvolvida (intensiva ou extensiva). Deve-se adicionar, ainda, as diferenças introduzidas pela diversidade de preços de commodities. As altas dos preços das commodities no mercado nacional e internacional ajudam a explicar a expansão da produção agrícola no Cerrado. 
Mesmo com esta expansão da fronteira agrícola, a produção brasileira de grãos está cada vez mais distante dos grandes centros econômicos e dos portos do Sudeste e Sul do Brasil. Segundo Caixeta Filho e Gameiro (2001), a produção mecanizada da soja na região dos Cerrados com objetivos de exportação, e a abertura de estradas, modificou de forma significativa a paisagem do CentroOeste, e constituiu a base de desenvolvimento na região. A mecanização da produção e a alta produtividade da região dos Cerrados estimularam a elaboração de projetos de infraestrutura para viabilizar o escoamento das cargas agrícolas em direção ao mercado nacional e/ou internacional.

Cabe ressaltar que há uma tendência no Cerrado cada vez mais forte da passagem de atividades extensivas (pecuária praticada em pastos naturais) para atividades intensivas (pecuária intensiva ou culturas) que tendem a absorver mais mão de obra por unidade de terra. Esse é o caso típico em Goiás e no Mato Grosso, estados que nas últimas décadas vêm transformando áreas de pecuária tradicional (pouco absorvedoras de mão de obra) em áreas de lavoura empresarial (soja e milho), com a utilização de tecnologias modernas (tratores, implementos mecânicos, colheitadeiras, aviões agrícolas). Essas lavouras são beneficiadas por financiamentos da produção através de crédito rural subsidiado, como é o caso do FCO (Fundo Constitucional de Financiamento do Centro-Oeste) ou BNDES (Banco Nacional de Desenvolvimento Econômico e Social).

Essa elevada taxa de crescimento, em conjunto com todo esse processo de transformação econômica, fornece um cenário importante para expansão da produção agropecuária no território da FICO. Essa expansão produtiva deverá contribuir para o crescimento e desenvolvimento econômico da região. Nesse sentido, quais as condições fundamentais exigidas para que a FICO se complete? Quais são as limitações externas que precisam ser enfrentadas?

Essa região da FICO, sendo de grande extensão territorial e deficiente em transportes, inclusive internamente, promove desigualdade espacial dentro de seu território devido à incapacidade de transporte e interligações entre suas diversas microrregiões. Neste aspecto, é importante destacar que a construção da ferrovia de interligação do Centro-Oeste, que se comunicará com a ferrovia Norte-Sul em Campinorte (GO), passando por Água Boa e Lucas do Rio Verde em Mato Grosso, abre uma perspectiva interessante de integração inter-regiões que proporcionará uma redução das desigualdades espaciais internas. Assim, para garantir o eficiente gerenciamento do transporte multimodal na região, é necessária uma infraestrutura para a intermodalidade tal que permita a eficiência do transbordo (tempo e custos sejam reduzidos) e o acompanhamento da carga para a programação da cadeia logística.

Vislumbra-se ainda como oportunidade futura com a FICO uma mudança substancial na base produtiva da região com um processo de agroindustrialização em que empreendedores possam investir na transformação de grãos e pecuária em 
produtos que gerem mais valor agregado. Um bom exemplo é o caso da soja que pode ser transformada em óleo e farelo, reduzindo os riscos de comercialização, considerando o incremento anual e a ocupação de áreas, bem como gerar maior valor agregado na região.

Portanto, caso ocorram investimentos na agroindustrialização, é de que no médio e longo prazos têm-se a perspectiva de que a pauta de exportações da região se diversifique com a inclusão de produtos agroindustriais, gerando mais mercados consumidores para produtos dos estados de Mato Grosso e Goiás, como o próprio mercado interno do Brasil. Por razões históricas de ocupação econômica, até hoje não existe uma infraestrutura adequada, em condições de transportar grande capacidade de carga, que possa fazer conexão desta região com outras regiões do País, apesar de nas últimas décadas a utilização dos princípios logísticos ter sido valorizada, visando melhor eficiência das operações de transporte, que possam em alguns casos determinar as vantagens competitivas de um dado sistema (FICI, 2007).

Vale lembrar que uma nova configuração geográfica do complexo da soja brasileira está se formando, em função de empreendimentos nos sistemas de transporte nas áreas dos Cerrados, principalmente a Ferrovia Norte-Sul, que tem se transformado em um corredor de exportação em direção ao porto de Itaqui (MA). Portanto, a perspectiva de integração do transporte ferroviário com o rodoviário implica no processo de relacionar as necessidades de circulação com as atividades econômicas que a região gera ou poderá gerar.

Ainda persiste um problema no sistema produtivo da região Centro-Oeste, especialmente ao longo da FICO, que é o direcionamento do produto em grãos para os estados do Sul e Sudeste, onde se localizam muitas empresas esmagadoras, portos exportadores e grande parte da infraestrutura de armazenagem e comercialização de grãos. Portanto, a viabilidade do sistema de transporte pela FICO consiste não apenas no aumento da produção de grãos no Centro-Oeste, como em um mecanismo para encurtar a grande distância e para reduzir o alto custo do frete que essa região apresenta.

\section{Conclusões e recomendações para pesquisas futuras}

Há em curso no Brasil um esforço, pelo governo e pela iniciativa privada, de melhora do desempenho operacional do sistema de transporte de cargas por meio de investimentos e revitalização da malha ferroviária. Mesmo com os recentes avanços, ainda são muitos os desafios a serem superados para que o transporte ferroviário brasileiro alcance patamares internacionais de referência. Historicamente, os investimentos realizados em ferrovias foram direcionados praticamente para as regiões Sudeste e Sul. Mesmo assim, há uma pequena 
densidade ferroviária no país, quando comparado com outras nações, especialmente na região Centro-Oeste, fronteira de expansão agrícola.

A mensuração do impacto da implantação de uma ferrovia pode ser feito pela análise macroeconômica de uma região. Trazem benefícios, como no caso de ferrovia que corta cidades ou serve para escoar a produção de uma região para o resto do país ou para o mundo. Há ainda o efeito transbordamento, quando o ganho de acesso de uma região é aproveitada por outra.

O trabalho mostra que o desenvolvimento da malha ferroviária permite reduzir a distância econômica entre os centros produtivos e seus mercados destino - tanto em nível nacional como internacional. Investimentos neste segmento podem afetar de forma significativa o crescimento econômico setorial (indústria, comércio, serviços e agropecuária). Caso este resultado seja verificado, investimento neste tipo de infraestrutura pode ser instrumento importante de política de desenvolvimento regional, de integração produtiva regional, com criação e fortalecimento de encadeamentos produtivos para trás e para frente.

Por ser um projeto em construção, a FICO precisa ser pensada em uma agenda de desenvolvimento regional. Uma infraestrutura ferroviária necessita gerar escalas de produção eficientes com o desenvolvimento de vantagens competitivas em sua área de influência para que possa alcançar um maior grau de especialização produtiva. A região da FICO é caracterizada por uma área de expansão da agropecuária centroestina que pode ser transformada futuramente em uma área de agroindustrialização. Nesse aspecto, existe um grande campo de ação para que esta ferrovia seja construída de forma que não seja apenas um corredor de transporte de cargas, mas um catalisador de inclusão produtiva e social.

\section{Referências}

ANT'T. Agência Nacional de Transportes Terrestres. Evolução do transporte ferroviário. 2014. Disponível em: http://www.antt.gov.br/index.php/content/ view/15884/Evolucao do Transporte Ferroviario.html. Acesso em: 23 set. 2015.

BARAT, Josef. Transportes e industrialização no Brasil no Período 18851985. Rio de Janeiro: Biblioteca do Exército, 1991.

Corredores de transportes e desenvolvimento regional. Revista Pesquisa e Planejamento Econômico IPEA, 2(2), p. 301-338, dez., 1972.

BARROS, A. R.; RAPOSO, I. Dotação de infraestrutura como limitante para redução de disparidades regionais no Brasil. In: II Encontro da Associação Brasileira de Estudos Regionais. Anais... São Paulo, 2002. 
BNDES. Banco Nacional de Desenvolvimento Econômico e Social. Dez anos do Programa Nacional de Desestatização: as concessões ferroviárias. 2000. Disponível em: http://www.bndes.gov.br/SiteBNDES/export/sites/default/ bndes pt/Galerias/Arquivos/conhecimento/seminario/ferro.pdf. Acesso em: 23 set. 2015.

CAMPOS NETO, C. A. S. et al. Gargalos e demandas da infraestrutura ferroviária e os investimentos do PAC: mapeamento Ipea de obras ferroviárias. Brasília: Ipea, 2010 ('Texto para Discussão, n. 1465).

CAIXETA FILHO, José Vicente; GAMEIRO, Augusto Hauber. Transporte e Logística em Sistemas Agroindustriais. São Paulo: Atlas, 2001.

CASTRO, N. P. Expansão agrícola nos cerrados: o papel das políticas de preços mínimos, de crédito rural e de transportes. IPEA, 2001. (Relatório de pesquisa).

DE PAULA, Dilma Andrade. As ferrovias no Brasil: análise do processo de erradicação de ramais. In: II Congreso de Ferrocarriles. Anais... Aranjuez, 2000.

ESALQ-LOG. Universidade de São Paulo. Escola Superior de Agricultura "Luiz de Queiroz". Modelo matemático de otimização logística para o transporte multimodal de safras agrícolas pelo corredor Centro-Oeste. Piracicaba, 2009.

FICI, Ricardo Petrillo. As ferrovias brasileiras e a expansão recente para o Centro-Oeste. 2007. 339 f. Tese (Doutorado em Geografia Humana). Universidade de São Paulo. 2007.

GALVÃO, Olímpio J. Desenvolvimento dos transportes e integração regional no brasil: uma perspectiva histórica. Planejamento e Políticas Públicas - IPEA, n. 13, 2009.

GEIPOT. Empresa Brasileira de Planejamento de Transportes. Corredores estratégicos de desenvolvimento. Alternativas para escoamento de soja para exportação. Brasília: GEIPOT, 2001.

IBGE. Fundação Instituto Brasileiro de Geografia e Estatística. Produção agrícola. Rio de Janeiro: IBGE, 2015. Disponível em: http://www.sidra.ibge.gov.br/bda/agric/default.asp?z $=t \& o=11 \& i=P$. Acesso em: 23 set. 2015. 
. Contas regionais. Rio de Janeiro: IBGE, 2015. Disponível em:

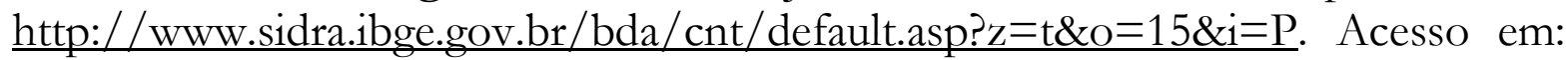
23 set. 2015.

LANNA, Ana Lúcia Duarte. Ferrovias no Brasil 1870-1920. História econômica \& história de empresas, v. 8, n. 1, 2012.

NAZÁRIO, P.; WANKE, P.; FLEURY, P F. O papel do transporte na estratégia logística, 2000. Disponível em: http://www.cel.coppead.ufrj.br/fspublic.htm. Acesso em: 23 set. 2015.

SILVEIRA, Márcio Rogério. A importância geoeconômica das estradas de ferro no Brasil. 2003. 454 f. Tese (Doutorado em Geografia). Universidade Estadual Paulista (UNESP), Presidente Prudente, 2003.

Plano Nacional de Logística e Transportes (PNLT). Relatório executivo 2001. Disponível em: http://www.transportes.gov.br/conteudo/2820-pnlt-relatorioexecutivo-2007.html. Acesso em: 23 set. 2015.

Programa de Investimentos em Logística (PIL). Relatório executivo 2012. Disponível em: http://www.planejamento.gov.br/assuntos/programa-deinvestimento-em-logistica-pil/ferrovias. Acesso em: 23 set. 2015.

VALEC Engenharia, Construções e Ferrovias S.A. Estudos de alocação de demanda e micro-localização do arranjo geral. Trecho Açailândia - Porto Nacional. 2006.

. Relatório de gestão do exercício de 2009. Disponível em: http://www.valec.gov.br/documentos/processos contas/relatorioGestao2009.pd f. Acesso em: 23 set. 2015 . 
Endereço para correspondência:

Jeferson de Castro Vieira - jcastrovieira@gmail.com Avenida Universitária, 1440, Setor Universitário 74.605-010 Goiânia/GO, Brasil

72 | Revista Brasileira de Desenvolvimento Regional, Blumenau, 3 (2), P. 55-72, primavera de 2015 